\title{
Experiência em website de marca-país e a formação da imagem de destino turístico: um estudo na Islândia
}

\author{
Experience on country brand website and the formation of tourist \\ destination image: a study in Iceland
}

\section{Experiencia en sitio web de marca país y la formación de la imagen de destino turístico: un estudio en Islandia}

\author{
Dirceu Tornavoi de Carvalho ${ }^{1}$ \\ Luciana Brandão Ferreira ${ }^{2}$ \\ Flávio Notomi Kanazawa ${ }^{3}$ \\ Priscilla Mendes Machado ${ }^{4}$ \\ Janaina de Moura Engracia Giraldi ${ }^{5}$
}

\begin{abstract}
Resumo: A pesquisa visa verificar se a experiência em websites de marcas-país influencia a imagem e a atratividade de um destino turístico na mente dos consumidores, bem como sua intenção de visitá-lo. Foi conduzido um estudo pré-experimental do tipo pré-teste/pós-teste de um único grupo com uma amostra de 30 estudantes de graduação de uma universidade paulista. $O$ tratamento consistiu em expor os sujeitos da pesquisa ao site turístico oficial da Islândia. As variáveis dependentes foram a percepção de atratividade turística e a intenção de visitar a Islândia. A avaliação da experiência de navegação foi medida utilizando escalas da literatura de comportamento de consumidor online. As duas hipóteses são: (1) a experiência online positiva influencia positivamente a formação da imagem do destino e (2) influencia positivamente a intenção de visita-lo, e ambas foram sustentadas pelos testes estatísticos de comparação de médias antes e após o tratamento. A análise de conteúdo de questão aberta, realizada após o tratamento, mostrou o efeito que o conhecimento adquirido por navegação prazerosa tem na formação da imagem e no aumento da intenção de visita um destino turístico.
\end{abstract}

Palavras-chave: Imagem de destino turístico. Experiência online. Website oficial de marca-país. Islândia.

Abstract: The research aims to verify if the experience with country brands website influences the image and attractiveness of a touristic destination in the consumers' minds as also in their intention to visit the destination. A pre-test/post-test pre-experimental study with a 30 undergraduate students sample in a university of São Paulo was conducted. The treatment consisted of exposing the subjects to the Iceland official touristic site. The dependent variables were the touristic attractiveness perception and the intention to visit Iceland. The evaluation of the browsing experience was measured using scales of online consumer behavior literature. The

\footnotetext{
1 Universidade de São Paulo (USP). E-mail: tornavoi@usp.br

2 Universidade de São Paulo (USP). E-mail: bfluciana@gmail.com

${ }^{3}$ Universidade de São Paulo (USP). E-mail: flavio.nk@gmail.com

4 Universidade de São Paulo (USP). E-mail: priscillamachado@usp.br

5 Universidade de São Paulo (USP). E-mail: jgiraldi@usp.br
} 
two hypotheses were: (1) that positive online experience positively influences the destination image formation and (2) positively influences the intention of visit, were supported by statistical means comparison tests before and after treatment. The content analysis of the open question, performed after treatment, showed the effect that the knowledge acquired by pleasurable navigation have in shaping the image and increasing the intention of visiting a touristic destination.

Keywords: Touristic Destination Image. Online experience. Official country brand website. Iceland.

Resumen: La investigación tiene como objetivo verificar si la experiencia en sitios web de marcas con países influye en la imagen y el atractivo de un destino turístico en la mente de los consumidores, así como la intención de visitarlos. Se realizó un estudio pre-experimental de tipo de pre-prueba / post-prueba de un único grupo con una muestra de 30 estudiantes de pregrado de una universidad paulista. El tratamiento consistió en exponer los temas de la investigación en el sitio oficial de turismo de Islandia. Las variables dependientes fueron la percepción de los atractivos turísticos y la intención de visitar Islandia. Se midió la evaluación de la experiencia de navegación utilizando escalas de la literatura del comportamiento del consumidor en línea. Las dos hipótesis: (1) que la experiencia en línea positiva influya positivamente en la formación de la imagen del destino e (2) influya positivamente en la intención de visitarlo, fueron sustentadas por pruebas estadísticas de comparación de medias, antes y después del tratamiento. El análisis de contenido de cuestión abierta, realizada después del tratamiento mostró el efecto que el conocimiento adquirido por la navegación placentera tiene en la formación de la imagen y en el aumento de la intención de visitar un destino turístico.

Palabras clave: Imagen de destino turístico. La experiencia en línea. Sitio web oficial de marca país. Islandia.

\section{INTRODUÇÃO}

O turismo é uma atividade do setor de serviços e, assim, apresenta as características de intangibilidade, heterogeineidade, inseparabilidade e perecibilidade que the são peculiares (Gronroos, 2004). As viagens de turismo apresentam ainda outra característica importante que é o hedonismo, isto é, estão relacionadas ao prazer. Isso traz um desafio aos gestores da área em criar comunicações que contribuam com percepções positivas em relação a um destino turístico nos seus potenciais consumidores. Uma forma de se fazer isso, segundo Zeithaml e Bitner (2003), é tentar tornar tangível o intangível por meio das comunicações de marketing.

Entre os meios de comunicação de marketing atuais, a internet tem sido cada vez mais acessada não apenas para a busca de informações sobre destinos turísticos, mas também para efetuar compras. Ademais, seus inúmeros recursos auxiliam em tornar a experiência online com o destino mais tangível.

Segundo a Organização Mundial de Turismo (OMT, 2003), uma pesquisa sobre turismo e estilo de vida, realizada pela Concierge em 2000, mostrou que, entre a população dos Estados Unidos, a internet já havia se tornado a primeira fonte de informações consultada ao se escolher ou se planejar uma viagem. Dados mais atuais do Brasil indicam que $91 \%$ dos internautas brasileiros pesquisam viagens pela web (PANROTAS, 2010). Em 2012, dezesseis milhões de brasileiros visitaram websites de turismo (E-commerce news, 2012).

Na decisão sobre visitar um destino, a imagem é um determinante importante para os turistas (Rezende-Parker et al., 2003). Para Hung, Lin, Yang e Lu (2012) a imagem do destino é formada pela interação entre fatores internos do consumidor e fatores do ambiente externo. Assim, o contato inicial do consumidor com o destino por meio de um website planejado é um fator que pode influenciar a formação da imagem do destino na mente do potencial turista.

Dentre as várias formas de contato via internet que o potencial consumidor pode ter com um destino específico, este trabalho destaca o website oficial que muitos países mantêm para pro- 
mover o turismo em suas diversas regiões, denominado website de marca-país. Em geral esses websites são geridos por Marketing Destination Organizations (DMOs), instituições sem fins lucrativos, geralmente públicas ou público-privadas, responsáveis pela divulgação do destino, usando entre outras ferramentas os websites (Fernandez-Cavia et al., 2014).

Embora a imagem de destino turístico seja uma área de investigação acadêmica por quase 30 anos, ainda são recentes os estudos que relacionem o ambiente virtual na formação de imagem do destino turístico. Alguns estudos como de Fernández-Cavia et al. (2014) e Del Vasto-Terrientes et al. (2015) abordam análises quantitativas da eficácia e atratividade dos websites oficiais por meio de rankings, como o Web Quality Index. Este artigo, contudo, visa capturar a opinião de possíveis consumidores do destino a partir da experiência de navegação online, uma vez que estes são os usuários das informações oferecidas pelo website. Nesse sentido o objetivo deste artigo é verificar se a experiência em website de marca-país influencia os consumidores no processo de formação da imagem do país como destino turístico.

A relevância do estudo se dá não apenas pela relevância da internet no processo de decisão de uma viagem como vários autores destacam (Corrêa, 2012; Fernández-Cavia et al., 2014; Del Vasto-Terrientes et al., 2015, Alzua-Sorzabal et al., 2015), mas também pela importância de estudos voltados não só a websites comerciais, como também a websites oficiais de turismo e como eles podem auxiliar na divulgação do destino já que esses websites não têm um intuito direto de venda. Para Cooper et al. (2007), tais organizações de marketing do setor público agem como instrumentos para atrair o consumidor.

Dessa forma, este estudo contribui tanto para fins acadêmicos por ser um assunto ainda pouco abordado e com lacunas, quanto para fins gerenciais uma vez que são discutidos aspectos relevantes para a gestão de websites de turismo (Li et al., 2009), a partir da experiência online do potencial consumidor.

\section{REFERENCIAL TEÓRICO}

O referencial teórico para elaboração do artigo se baseia nos seguintes pilares: imagem de país e de destino turístico, marca-país e experiência online.

\subsection{Imagem de país e de destino turístico}

A popularização da internet, o desenvolvimento de novas tecnologias e outras forças contemporâneas acentuaram profundamente as transformações sociais e econômicas causadas pela globalização. Entre elas estão o aumento do fluxo de pessoas entre os países, do comércio e das transações financeiras internacionais, de modo que um número cada vez maior de países passou a competir por investimentos estrangeiros, por turistas, imigrantes e exportações, desenvolvendo programas e ações para estimulá-los. Diante disso, muitos países passaram a adotar estratégias de comunicação, desenvolvimento e gestão de marcas para se diferenciarem de seus concorrentes nessa competição global. Em suma, países, e não somente as empresas, buscam atualmente destaque e reconhecimento no contexto mundial (Fetscherin, 2010; Stock, 2009; Konecnik, \& Gartner, 2007; Fan, 2010).

Assim, nota-se a importância dos esforços para que o país tenha uma boa imagem junto aos públicos estrangeiros, já que essa imagem é capaz de influenciá-los em decisões como adquirir pro- 
dutos, realizar investimentos e também visitar tal país (Nebenzahl, 2007; Diamantopoulos, Schlegelmilch \& Palihawadana, 2011; Hynes et al., 2014).

Todos os países possuem uma imagem, que pode ser positiva ou negativa (Nebenzahl, 2007). De acordo com Hynes et al. (2014), há um crescente consenso na literatura de que a imagem de um país pode ser definida como uma impressão geral que os consumidores possuem a respeito de um determinado país. Hakala e Lemmetyinen (2011) complementam o conceito afirmando que ela é formada a partir de conhecimentos e experiências prévias que se tem com relação ao país, podendo ser afetada por estereótipos a respeito de sua população e suas condições econômicas, sociais e políticas.

Nadeau et al. (2008) diferenciam a imagem dos produtos de um país (product-country image) e a imagem de um destino turístico (tourism destination image). Na visão dos autores, o primeiro conceito está relacionado às percepções a respeito de um país no que se refere à aquisição de produtos cuja fabricação está ligada a esse país, seja na produção, na montagem, no design, na localização da sede da empresa, entre outros aspectos, enquanto o segundo conceito se refere a percepções que se tem de determinado destino turístico.

Em uma das primeiras definições sobre o assunto, Crompton (1979) define a imagem de destino turístico como a soma de crenças, ideias e impressões que se tem de uma localidade. Para Parenteau (1995) a imagem de destino é um pré-disposição favorável ou desfavorável que o público em geral, e operadores turísticos em particular, têm do local turístico. Nota-se que, embora haja aspectos similares entre imagem de país e imagem de destino, a primeira é mais abrangente, focando no país como um todo, ao passo que a imagem destino foca nas impressões a respeito de uma dada localidade que pode ser um país ou de um destino turístico dentro dele.

Em uma conceituação mais recente, Tasci, Gartner e Cavusgil (2007) definem imagem de destino turístico como um sistema interativo de pensamentos, sentimentos, opiniões, visualizações e intenções referentes ao um destino, definição que leva em consideração a influência dessa imagem no processo de tomada de decisão de compra dos turistas. Em sintonia a isso, Chen e Tsai (2007) discorrem que, além de influenciar o processo de escolha de um destino turístico, essa imagem também influencia o comportamento pós-compra dos turistas, o que abrange uma possível intenção de retorno e o desejo de recomendar o destino a outras pessoas, sendo a internet uma importante ferramenta para a busca e troca de informações turísticas.

Para Smallman e Moore (2010), os processos de tomada de decisão dos turistas são complexos, envolvendo diversas decisões menores, partindo do local para onde o indivíduo viajará e abrangendo as diferentes atividades que serão realizadas no destino selecionado. Ainda de acordo com os autores, baseadas em fatores contextuais, percepções e julgamentos definidos pelo viajante, muitas dessas escolhas possuem riscos relativamente altos, uma vez que só é possível saber se a experiência de viagem será satisfatória quando ela é de fato vivenciada.

Dadas as definições acima, afirma-se que a presente pesquisa possui foco na imagem de destino turístico, cujas pesquisas iniciaram-se com Hunt em 1971. Para ele, essa imagem está relacionada às impressões que as pessoas detêm cerca de um local em que não residem (Gallarza; Saura \& García, 2002). Baloglu e McCleary (1999) destacam em seu modelo que a imagem de destino é formada a partir de fatores de estímulo e características dos turistas. E esses estímulos advêm, entre outros, de fontes de informação externa. Dentre os aspectos que têm sido estudados como influenciadores na formação da imagem do destino pelo consumidor estão: (1) tempo de permanência no local destino (Fakeye \& Crompton 1991); (2) impressões de visita anterior (Dann, 1996); (3) caracte- 
rísticas pessoais do consumidor (Stern \& Krakover, 1993); (4) experiências virtuais com destino via navegação na Internet (Cho, Wang \& Fesenmaier, 2002).

Para Doolin, Burgess \& Cooper (2002), o conteúdo do website de um destino turístico é muito importante porque influencia diretamente sua imagem percebida e possibilita ao consumidor a criação de uma experiência virtual. Tal experiência não impõe a presença física do cliente no destino, mas, do mesmo modo, provoca alterações na sua imagem. A interação com o ambiente do website provoca um forte impacto no consumidor, mas também na opinião que irá ser transmitida para familiares, amigos e outros utilizadores, seja em relação ao website ou em relação ao destino (Rafael \& Almeida, 2014).

Em seu estudo Pai, Xia, Wang (2014), observaram a eficácia de websites oficiais de cinco destinos turísticos internacionais, encontrando uma relação linear positiva entre a complexidade e o desempenho do site, ou seja, o nível de desempenho é maior se o site foi implementado com tecnologias mais sofisticadas.

Os resultados e insights dos estudos podem dar recomendações às organizações gestoras dos destinos turísticos fornecendo explicações para a relação entre os esforços de e-marketing e o desempenho real dos websites. Na perspectiva da gestão online dos destinos, Thomaz et al. (2015) destacam também a importância do monitoramento em redes sociais. Essas informações podem ser utilizadas para elaborar novas estratégias, tomar decisões operacionais e elaborar novos produtos e serviços, sendo aplicadas também na atualização dos próprios websites oficiais.

As imagens dos destinos turísticos evoluem com o tempo, mesmo sem a ação das organizações por elas responsáveis. Caso os países não deem a devida atenção, correm o risco de que suas imagens continuarem sendo baseadas em estereótipos e associações desatualizadas ou inapropriadas, gerando consequências negativas no curto e no longo prazo. Assim, é fundamental que países e destinos turísticos avaliem regularmente suas imagens perante os públicos de interesse e trabalhem para engrandecê-las ou alterá-las.

Esse trabalho é conhecido como gestão da marca-país, referindo-se à utilização de conceitos, estratégias e práticas de marcas em prol da melhoria da imagem de um país de forma a obter alguma vantagem e/ou diferenciação na competição global por investimentos, negócios, turistas e imigrantes (Fan, 2010; Anholt, 2007), como pode ser visto no tópico que segue.

\subsection{Gestão da Marca-País}

O turismo se beneficia de uma marca-país forte e a imagem de um lugar é considerada um fator-chave para investimentos internacionais (Hakala, Lemmetyinen, \& Kantola, 2013). De acordo com Anholt (2005), o planejamento de uma marca-país deve definir uma visão estratégica realista, competitiva e convincente para o país. Com base nessa visão, deve-se criar ações e mecanismos para colocá-la em prática e comunicá-la aos públicos de interesse. Quando bem gerenciada, uma marcapaís é capaz de afetar positivamente a confiança interna e o desempenho externo de um país.

Para obter sucesso com uma marca-país, Kotler e Gertner (2004) complementam dizendo ser necessário adotar ferramentas de gestão estratégica de marketing que incluem compreender os elementos que influenciam a atratividade do país, monitorar o ambiente externo e encontrar oportunidades, ameaças bem como identificar as forças competitivas atuantes nesse ambiente. Além disso, o gerenciamento da marca-país deve envolver governo, empresas e cidadãos em torno de 
uma visão comum para o país. Os autores definem as etapas abaixo para um enfoque estratégico no gerenciamento de uma marca-país:

- Analisar e definir seus principais pontos fortes e fracos e suas principais oportunidades e ameaças;

- Selecionar setores de atividade, personalidades, marcos naturais e eventos que possam formar a base de uma sólida estratégia de marca e uma narrativa interessante;

- Desenvolver um conceito "guarda-chuva", abrangente, que cubra e seja coerente com todas as atividades relativas ao estabelecimento e desenvolvimento de sua marca. Entre os conceitos possíveis, o país pode ser associado a prazer, qualidade, segurança, sinceridade, progresso, etc.;

- Destinar fundos nacionais suficientes para cada atividade relativa ao desenvolvimento de sua marca a fim de garantir que tenha impacto significativo;

- Criar controles de exportação para garantir que todos os produtos exportados sejam confiáveis e atinjam o nível de desempenho prometido.

Uma das áreas de atuação da gestão de marca-país e de destinos turísticos é o desenvolvimento de um ambiente na internet que proporcione uma experiência online positiva para públicosalvo selecionados. No presente estudo os potenciais turistas formam o foco principal.

\subsection{Experiência online}

Uma das primeiras contribuições à literatura de experiência do cliente foi dada por Holbrook e Hirschman (1982) ao desenvolverem um estudo teórico comparando duas formas de interpretar o comportamento do consumidor - o modelo de processamento de informação e a visão experiencial. Segundo os autores, até então, grande parte dos estudos sobre comportamento do consumidor davam ênfase em escolhas racionais, em uma abordagem de processamento de informação. Entretanto, teóricos começaram a questionar a hegemonia dessa perspectiva, alegando que ela negligenciava fenômenos de consumo importantes como fantasias, sentimentos e diversão, englobados pela visão experiencial. A partir desse ensaio seminal desdobrou-se uma linha de pesquisa sobre experiência do cliente, exemplificada pelos estudos realizados por Addis e Holbrook (2001), Arnould e Price (1993), Brakus, Schmitt e Zarantonello (2009), Carù e Cova (2007), Gentile, Spiller e Noci (2007) e Holbrook (2006).

Nos últimos anos, com a popularização da internet como meio de venda de produtos, fonte de informação e de serviços, a visão experiencial de consumo foi introduzida no ambiente da Web, iniciando pesquisas referentes à experiência online dos clientes (OCE, sigla em inglês). Segundo Constantinides (2004), a experiência na Web engloba elementos como busca, navegação, localização, seleção, comparação e avaliação de informações, bem como interação e negociação online com a empresa ou organização patrocinadora ou ofertante. Impressões e ações do cliente virtual são influenciadas pelo design, eventos, emoções, atmosfera e outros elementos vividos durante a interação com um determinado site. A gestão desses elementos visa induzir a boa vontade do cliente e afetar o resultado final da interação online.

O estudo de Constantinides (2004) identificou na literatura elementos influenciadores do comportamento de compra online, sendo agrupados pelo autor em três categorias principais: fatores de funcionalidade, fatores psicológicos e fatores de conteúdo. Fatores de funcionalidade incluem elementos de usabilidade e interatividade e melhoram a experiência online, apresentando ao cliente bom funcionamento, facilidade de exploração do site, rapidez e interatividade. Já os fatores psicoló- 
gicos comunicam integridade e credibilidade a fim de persuadir os clientes a parar, explorar o site e interagir online. Por fim, os fatores de conteúdo são referentes aos elementos criativos e do marketing mix da empresa presentes no site.

Em estudo semelhante, Rose, Hair e Clark (2011) propuseram um modelo de antecedentes da OCE que inclui: processamento da informação, facilidade de uso percebido, utilidade percebida, benefícios percebidos, percepção de controle, habilidade, propensão a confiar, risco percebido e prazer. $O$ modelo também identifica duas principais consequências da OCE: a satisfação do cliente e a intenção de recompra. Segundo os autores, o modelo proposto sugere que os gestores precisam estar cientes de que, enquanto o desempenho funcional de um site é importante, também é essencial compreender o estado vivencial e as respostas dos clientes susceptíveis de serem geradas pelo website.

Nesse sentido, cada vez mais estudos têm sido feitos voltados a compreender a influência da experiência online no comportamento do consumidor de turismo. Janach et al. (2014) destacam, por exemplo, a diferença de influências para segmentos distintos em avaliações de acomodações no site Tripadvisor, sendo que o objetivo não é apenas prever com mais precisão os itens de interesse, mas também auxiliar na criação de experiências de interação mais persuasivas. Ainda voltado ao ambiente virtual, um novo conceito ganhou a atenção de pesquisadores e profissionais na última década, denominado de ecossistema de negócios digital. Esse conceito consiste em uma infraestrutura tecnológica que visa criar um ambiente digital para apoiar e reforçar redes entre empresas e partes interessadas que operam dentro de um setor, no caso o turismo, alterando a configuração estrutural do sistema de turismo e, especificamente, de destinos turísticos (Baggio \& Chiappa, 2014).

Os estudos citados, cada um a seu modo, mostram claramente a influência da navegação online em sites de turismo e busca de informação na internet como uma poderosa ferramenta influenciadora do comportamento do consumidor e de formação de imagem do destino turístico, no entanto ainda são encontrados poucos estudos focados nas possibilidades dos sites oficiais de turismo dos países. O estudo de Pai et al. (2014) é um dos exemplos onde é feita uma comparação de sites oficiais de turismo de países orientais, mas não enfoca a influência na imagem do destino a partir da navegação e sim a navegabilidade, facilidade de navegação, atratividade, criatividade do site. Já outros estudos pesquisados focam na imagem do destino, mas não necessariamente relacionado à experiência virtual como Hung et al. (2012), Hakala et al. (2013), Gao \& Bai (2014).

Desse modo, a presente pesquisa teve por objetivo entender qualitativamente e fazer medidas quantitativas acerca do efeito que a experiência de navegação em um website oficial de turismo tem sobre a imagem do país e a intenção de visitá-lo. Tais websites são usualmente cadastrados como "visit(nome do país).com" e amplamente utilizados como ferramentas de divulgação de destinos turísticos dentro do país.

A revisão da literatura permitiu formular duas hipóteses tentando refletir a influência da experiência online destes websites na imagem do destino turístico. Destaca-se o estudo realizado por Cho et al. (2002) que mostrou que os passeios virtuais e as informações presentes nestes sites possibilitam uma avaliação mais precisa da experiência que será desfrutada pelo viajante e a criação de uma história pessoal do destino, de modo a impactar na criação da imagem do destino. Diante disso, a seguinte hipótese foi proposta:

H1: A experiência online positiva influencia positivamente na formação da imagem do destino. 
Além disso, o estudo realizado por Pai et al. (2014) mostrou que websites eficazes podem atrair mais turistas e melhorar o nível de satisfação dos consumidores. Assim, a seguinte hipótese também foi proposta:

H2: A experiência online positiva influencia positivamente a intenção de visitar o destino.

As hipóteses aqui apresentadas foram verificadas por um estudo pré-experimental apresentado no tópico seguinte.

\section{MÉTODO}

Para o alcance do objetivo de verificar se a experiência com websites influencia os consumidores na formação da imagem de um destino turístico e na intenção de visitá-lo, foi realizado um estudo de natureza pré-experimental quantitativo com elementos qualitativos de verificação. $O$ desenho utilizado foi de pré-teste/pós-teste de um único um grupo (Malhotra, 2012). Em notação técnica o pré-experimento pode ser descrito por:

\section{$\mathrm{GE} \quad \mathrm{O} 1 \quad \mathrm{X} \quad \mathrm{O} 2$}

Onde GE é o grupo experimental e:

- O1 é a medida de intenção de visitar o destino turístico antes da exposição ao estímulo;

- X é o tratamento feito, no caso a navegação por 7 minutos no website oficial da Islândia $\mathrm{e}$;

- $\quad$ O2 é a medida de intenção de visitar o destino turístico depois da exposição do grupo experimental ao estímulo.

Diferentemente dos estudos experimentais, os pré-experimentais não envolvem a distribuição aleatória dos sujeitos aos tratamentos nem a utilização de grupos de controle. "São utilizados quando o pesquisador não tem controle sobre o processo de aleatoriedade e pressupõe que o pesquisador não possui controle pleno sobre a exposição dos sujeitos às manipulações da variável independente" (Hernandez, Basso, \& Brandao, 2014, p. 102). Como a variável independente foi a experiência com o website turístico oficial, não havia como precisar exatamente quais páginas seriam visitadas pelos sujeitos do grupo experimental, justificando o desenho adotado.

Geralmente, como apresentado por Akker, Kumar e Day (2001), são utilizadas amostras pequenas nos estudos pré-experimentais, por serem análises mais simples. Entretanto, os autores não deixam claro qual o número mínimo necessário para a realização deste tipo de estudo. Navidi (2012), com base no Teorema do Limite Central, declara que, para grande parte das populações, uma amostra correspondente a 30 ou mais elementos pode ser considerada como suficientemente grande para se aproximar da distribuição normal, tornando possível a realização de testes estatísticos. Logo, optou-se por utilizar uma amostra do tamanho de 30 neste estudo, de modo a possibilitar a realização de testes estatísticos e ainda enquadrar-se como uma pequena amostra.

O experimento foi realizado com 30 estudantes de graduação da Universidade na qual trabaIham os autores. A amostra foi do tipo não probabilístico por conveniência. Para o desenvolvimento do estudo, foi utilizado o site oficial da Islândia (www.visiticeland.com). A escolha por esse país ocorreu devido a três fatores. O primeiro foi pelo fato de a Islândia ser pouco conhecida pelos sujeitos e não ser um dos principais destinos turísticos internacionais. Segundo o relatório da Organização Mundial do Turismo (OMT, 2014), em 2012 a Islândia recebeu aproximadamente 673 mil turistas, representando 0,1\% da entrada de turistas na Europa. A título de comparação, a França, principal destino turístico do mundo, recebeu 83 milhões de turistas, representando 15,3\% da entrada de 
turistas na Europa. Já o Brasil recebeu 5,7 milhões de turistas no mesmo ano, representando 3,5\% da entrada de turistas na América. 0 segundo aspecto considerado foi o fato de o país apresentar uma variedade de atrações turísticas, a maior parte relacionada a aspectos naturais, como a existência de vulcões, campos de areia, montanhas, glaciares, cataratas e gêiseres (piscinas quentes de lama). O terceiro aspecto considerado foi o fato de a Islândia apresentar um website oficial composto por uma variedade de informações sobre o país, dispondo de dados sobre lugares a visitar, cultura da região, atrações turísticas, onde se hospedar, transportes, entre outros.

Além disso, o website oficial é interativo, apresenta um design atrativo e é de fácil utilização. Ressalta-se que, como o site selecionado não apresenta uma versão em português, a pesquisa foi realizada apenas com estudantes que tivessem conhecimento avançado na leitura do inglês. Destaca-se ainda que foram feitos cinco pré-testes para verificação do tempo necessário para a navegação no site e para verificação do entendimento das questões dos questionários.

\subsection{Instrumentos de medida}

As duas medidas, antes e após a exposição dos sujeitos ao site oficial da Islândia, foram feitas com questionários inseridos nos apêndices A e B. O instrumento preenchido pelos sujeitos antes da exposição (apêndice A) continha perguntas de filtro, de perfil, sobre o uso de websites "marcapaís", ou seja, sites oficiais de turismo do tipo "visit (nome do país).com" e uma questão aberta sobre o que conhecia sobre a Islândia. Por fim o primeiro instrumento apresentou as duas questões centrais do experimento. A primeira mediu, em uma escala de 0 a 10, a atratividade percebida pelos sujeitos acerca da Islândia como um destino turístico, sendo esta pergunta baseada em Li et al. (2009). A segunda teve por objetivo avaliar a intenção de visitar a Islândia e foi composta por três variáveis retiradas dos trabalhos de Knight e Kim (2007) e Diallo (2012) que utilizaram escalas de concordância de sete pontos.

O segundo questionário, aplicado após o tratamento (experiência de navegação no site oficial), foi composto por três partes. A primeira avaliava a experiência online, abordando aspectos relativos ao conteúdo da informação, facilidade de uso, atratividade visual e avaliação geral da experiência de navegação, com base nas escalas apresentadas no estudo de Gao e Bai (2014). A segunda parte repetia as medidas de avaliação de atratividade percebida e intenção de visitar a Islândia presentes no questionário pré-tratamento. Por fim uma pergunta, de caráter dissertativo, feita para verificar se houve mudança na imagem que os participantes tinham da Islândia após a experiência com o site e, em caso positivo, que a descrevessem.

Os dados obtidos foram submetidos à análise estatística utilizando o software SPSS 17. A análise de comparação de médias entre as mesmas variáveis antes e depois do tratamento utilizou teste de amostras pareadas e permitiu responder aos objetivos propostos pela pesquisa. Uma análise de conteúdo baseada em Bardin (2011) sobre as questões abertas proporcionaram aprofundamento e enriquecimento dos achados quantitativos.

\section{RESULTADOS}

\subsection{Perfil dos participantes}

Dos 30 sujeitos de pesquisa 20 eram do sexo masculino e 10 do sexo feminino, o que condiz 
com a realidade da faculdade que possui cursos com maior predominância de alunos que alunas. A idade dos participantes do experimento variou de 18 a 31 anos com prevalência de alunos entre 18 e 24 anos. Pouco mais da metade (17) já havia realizado alguma viagem para o exterior, sendo os principais lugares visitados: EUA, América Latina (Argentina, Paraguai, Uruguai e Chile) e Europa (França, Itália, Reino Unido, Espanha, Portugal, Alemanha). A maioria dos participantes (27) utiliza a internet par organizar suas viagens. Porém apenas 9 utilizam sites oficiais de turismo para esse intuito.

O conhecimento prévio dos sujeitos foi avaliado por meio de uma questão aberta que perguntava sobre a imagem que tinham da Islândia como destino turístico. A categorização das respostas feita por análise de conteúdo (Bardin, 2011) pode ser vista na tabela 1.

\begin{tabular}{lc} 
Tabela 1 - Imagem da Islândia como destino turístico & (pré-experimento) \\
\hline \multicolumn{1}{c}{ Imagem } & Frequência \\
\hline País com clima frio / Presença de neve & 14 \\
Paisagens naturais e exóticas & 8 \\
Montanhas e vulcões & 7 \\
Aurora boreal & 2 \\
Cultura peculiar & 2 \\
População pequena & 2 \\
País pobre & 1 \\
Nenhuma imagem & 5 \\
\hline
\end{tabular}

Apenas 5 dos participantes nada sabiam sobre o país foco. Os demais apresentavam conhecimento amplo, ainda que razoavelmente correto acerca das características gerais da Islândia. Entretanto, nenhum deles foi capaz de citar locais, destinos ou atrações específicas.

\subsection{Avaliação da experiência online}

Como as hipóteses do estudo relacionam experiência online positiva (Constantinides, 2004) com alterações na percepção da imagem e intenção de visita ao destino turístico (Alzua-Sorzabal et al., 2015), o primeiro conjunto de análises foi destinado a obter uma avaliação da qualidade da experiência vivenciada pelos sujeitos da pesquisa. Conforme mencionado anteriormente, foram utilizadas quatro categorias de avaliação da experiência online: conteúdo da informação, facilidade de uso, atratividade visual e experiência online geral, conforme Gao e Bai (2014). Os resultados estão na tabela 2 . 
Tabela 2 - Experiência online dos participantes

\begin{tabular}{|c|c|c|c|}
\hline & & Média & Desvio padrão \\
\hline & As informações são convenientes & 6,37 & 0,850 \\
\hline Conteúdo das & As informações são precisas & 5,70 & 1,179 \\
\hline \multirow[t]{4}{*}{ informações } & As informações estão atualizadas & 5,79 & 1,292 \\
\hline & As informações são completas & 5,63 & 1,189 \\
\hline & As informações são relevantes & 6,40 & 0,724 \\
\hline & Informações facilmente encontradas & 5,80 & 1,215 \\
\hline \multirow{4}{*}{$\begin{array}{l}\text { Facilidade de } \\
\text { uso }\end{array}$} & Navegação fácil, o site é simples & 6,10 & 1,322 \\
\hline & Site bem estruturado & 6,30 & 0,837 \\
\hline & Conteúdo disposto de forma organizada & 6,17 & 0,986 \\
\hline & O site é divertido & 5,53 & 1,383 \\
\hline \multirow{4}{*}{$\begin{array}{l}\text { Atratividade } \\
\text { visual }\end{array}$} & O site é imaginativo & 5,83 & 1,416 \\
\hline & O site é emocionante & 5,00 & 1,339 \\
\hline & As imagens da Islândia expostas no site são atrativas & 6,83 & 0,461 \\
\hline & $\begin{array}{l}\text { As informações apresentadas foram suficientes para formar um } \\
\text { imagem do destino turístico }\end{array}$ & 6,13 & 1,074 \\
\hline \multirow{2}{*}{$\begin{array}{l}\text { Experiência } \\
\text { online geral }\end{array}$} & A experiência online despertou o desejo de visitar a Islândia & 6,00 & 1,414 \\
\hline & $\begin{array}{l}\text { As imagens e a interatividade do site ajudaram a ter uma ima- } \\
\text { gem positiva sobre o destino turístico }\end{array}$ & 6,40 & 0,814 \\
\hline
\end{tabular}

Observando-se cada categoria de avaliação, é possível notar que:

- A relevância das informações apresentadas, com média de 6,40 foi destaque na categoria conteúdo da informação;

- Na categoria facilidade de uso, o destaque positivo foi para a estruturação do site, enquanto a facilidade de encontrar informações durante a navegação apresentou a menor média $(x=5,80)$;

- Quanto à atratividade visual, o destaque ficou com atratividade das imagens da Islândia expostas no site, enquanto os elementos emocionais marcaram médias bem inferiores;

- Por fim, experiência online geral foi a única a obter médias acima de 6 em todos os seus itens, sugerindo que a experiência foi apreciada pelos respondentes.

Como a escala de mensuração teve 7 pontos, o ponto de indiferença é 4. Observa-se que todos os itens obtiveram médias superiores a 4. Esse fato, aliado aos detalhes apresentados acima, permite concluir que a experiência geral com o website oficial da Islândia foi considerada positiva pelos sujeitos da pesquisa. Esse resultado vai ao encontro do que é destacado na literatura por Rose et al. (2011), que propõe um modelo onde os gestores precisam estar cientes de que, desempenho funcional de um site é importante, mas também é essencial compreender o estado vivencial e as respostas dos clientes susceptíveis de serem geradas pelo website. E essa resposta se dá somente a partir da experiência online.

\subsection{Efeitos da experiência online sobre a imagem do destino turístico}

Para verificar a primeira hipótese, ou seja: H1 - A experiência online positiva influencia positivamente na formação da imagem do destino, foram tomadas medidas, antes e depois da exposição dos sujeitos, acerca da atratividade da Islândia como destino turístico. O resultado comparativo desse indicador é apresentado na tabela 2 que mostra o teste de amostras pareadas realizado, bom como a média e desvio padrão antes e depois do experimento. 
Tabela 2 - Alterações na avalição da atratividade da Islândia como destino turístico

\begin{tabular}{|c|c|c|c|c|c|}
\hline & $T$ & Significância & & Média & Desvio Padrão \\
\hline \multirow{2}{*}{$\begin{array}{l}\text { De } 1 \text { a 10, quão atrativa é a Islândia } \\
\text { como destino turístico? }\end{array}$} & \multirow{2}{*}{$-7,276$} & \multirow{2}{*}{0,000} & Antes & 5,60 & 1,793 \\
\hline & & & Depois & 8,13 & 1,502 \\
\hline
\end{tabular}

Como pode ser observado na tabela, houve uma mudança na média da atratividade percebida de 5,60 antes para 8,13 após o experimento, em uma escala de 1 a 10, e essa mudança foi significativa ao nível de $\alpha=0,01$. Com base nesse resultado pode-se afirmar que a experiência online, já identificada como positiva no tópico anterior, influencia positivamente a imagem do destino, o que significa que a hipótese 1 foi sustentada. Tal resultado também encontra respaldo na literatura que destaca a importância dos websites na promoção da imagem do destino (Chol, Lehto \& O'leary, 2007; Tang \& Jang, 2012, Fernández-Cavia et al, 2013).

\subsection{Efeitos da experiência online sobre a intenção de visitar o destino turístico}

Para verificar a segunda hipótese, ou seja: H2 - A experiência online positiva influencia positivamente a intenção de visitar o destino, foram também tomadas medidas antes e após a exposição utilizando três variáveis. Os resultados são apresentados na Tabela 3 com o teste de amostras pareadas realizado, assim como a média e desvio padrão antes e depois da experiência de navegação no site oficial da Islândia.

Tabela 3 - Influência da experiência online na intenção de visitar a Islândia

\begin{tabular}{|c|c|c|c|c|}
\hline & $\mathbf{t}$ & Significância & Média & $\begin{array}{l}\text { Desvio } \\
\text { Padrão }\end{array}$ \\
\hline \multirow[t]{2}{*}{ Consideraria ir para a Islândia na próxima viagem } & $-5,673$ & 0,000 Antes & 3,13 & 1,525 \\
\hline & & Depois & 4,73 & 1,856 \\
\hline \multirow{2}{*}{$\begin{array}{l}\text { Existe forte possibilidade de ir à Islândia na próxima } \\
\text { viagem }\end{array}$} & $-4,812$ & 0,000 Antes & 1,79 & 1,013 \\
\hline & & Depois & 2,90 & 1,543 \\
\hline \multirow[t]{2}{*}{ Visitarei a Islândia no futuro } & $-5,026$ & 0,000 Antes & 4,37 & 1,402 \\
\hline & & Depois & 5,87 & 1,525 \\
\hline
\end{tabular}

Como pode ser observado na tabela, todas as três variáveis apresentaram aumento significativo das médias, indicando que a hipótese 2 é sustentada. A confirmação das duas hipóteses deste estudo demonstra a importância da gestão da imagem e da marca de um país na formação da intenção de visita, especialmente na situação em que os turistas possuírem conhecimentos limitados sobre os atributos de um destino antes de visitá-lo (Hakala, Lemmetyinen, \& Kantola, 2013) além de corroboram com a ideia do website oficial como um importante instrumento de informação do destino e consequente contribuição na formação de uma imagem positiva.

\subsection{Elementos qualitativos decorrentes do experimento}

Após o experimento, foi perguntado aos participantes se houve alguma mudança em relação à imagem que tinham a respeito da Islândia depois da navegação pelo website. A resposta foi positiva em 28 dos 30 casos. A navegação pelo website confirmou a imagem geral que a maioria dos participantes tinha em relação ao clima e à geografia do país. A beleza do website e das fotos das paisagens e dos atrativos naturais do país chamou a atenção de muitos, como pode ser evidenciado pelos 
verbatins: "o site é muito bonito e estimula muito o interesse pelo lugar" e "através do site, pude conhecer as belas paisagens, as características do lugar e de seus atrativos".

Adicionalmente, a experiência online ajudou na formação da imagem do país como destino turístico para aqueles que não possuíam imagem alguma a respeito da Islândia, além de gerar interesse, conforme sugerem os trechos abaixo:

- "Não conhecia antes e agora acho interessante."

- "Conheci as características do lugar e seus atrativos."

- "Melhorou meu conhecimento sobre os atrativos turísticos."

A navegação também contribuiu para mostrar aos respondentes que a Islândia possui muitos outros atrativos além dos relacionados a frio, neve e montanha, fato que gerou surpresa em algumas pessoas e despertou interesse em visitar o país. Os excertos abaixo ilustram tal aspecto:

- "Local muito mais atrativo do que eu imaginava, belas paisagens, opções de turismo diversificadas, seguro de se visitar."

- "Antes achava que era um lugar ártico, só com gelo e desabitado. Agora vejo que é mais diversificada."

- "A imagem que eu tinha era de uma região muito inóspita com montanhas e piscinas com águas quentes."

- "Pude observar diferentes atividades turísticas que são expressivas no país que eu não enxergava antes."

- "Imagem antes era superficial. Há muitas coisas e lugares a serem explorados. Várias atratividades."

- "Pude observar diferentes atividades turísticas que são expressivas no país que eu não sabia. Além de que a experiência de navegar no site já aumentou a vontade de conhecer a Islândia e explorar suas paisagens e cultura geral."

As atividades de aventura (ciclismo, trilhas, caminhadas) chamaram a atenção dos participantes, bem como as características culturais e gastronômicas do país, desconhecidas pelos participantes antes da interação com o website. Os trechos ilustram essa conclusão:

- "As fotos do site mostram paisagens muito bonitas e pessoas alegres. Percebi que o país possui não só atrativos de frio e montanha, mas também parece ter atividades culturais interessantes e também opções para quem gosta de pedalar, caminhar, nadar. Com certeza despertou minha curiosidade de visitar a Islândia."

- "Após navegar o site me interessei pela gastronomia e pelas cidades. Gosto de cidades com casas charmosas e cafés antigos onde posso sentar e provar comidas e bebidas diferentes e típicas da região."

- $\quad$ "Ao visitar o site conheci muitas coisas que não sabia sobre o país. Pessoas pedalando e fazendo caminhadas em paisagens bonitas, cavernas, piscinas naturais. A cultura parece ter traço único, diferente do restante da Europa. Passei a gostar do país." 
- Imaginava que a Islândia era um destino apenas para se ver neve, agora vejo que o lado cultural é muito forte e a culinária também, além de ter vários passeios turísticos para se fazer."

- "Apesar de o site ter confirmado minha imagem de ser um país montanhoso e frio, fiquei surpresa pelas outras atrações do país. Os lados cultural, gastronômico e aventureiro do país eram desconhecidos pra mim."

Assim, o website, ao apresentar informações referentes ao país de modo simples, prático e visualmente bonito, aumenta o conhecimento dos internautas e auxilia na formação de uma imagem para os que nada conheciam sobre o país e gera surpresa ao apresentar características e atrativos antes desconhecidos.

Ao identificar que a experiência online vivenciada pelos participantes da pesquisa foi positiva, que a imagem construída também foi positiva e que a experiência online impactou na imagem existente dos participantes, pode-se afirmar que a experiência online positiva influenciou positivamente na formação da imagem do destino. Ressalta-se que, apesar de não ter havido uma alteração significativa nos tipos de destino turístico que os participantes associam à Islândia, as medidas utilizadas para se testar a atratividade do país como destino turístico e os depoimentos qualitativos sugerem que houve a alteração significativa da imagem do país a partir da experiência que os sujeitos tiveram com o site.

\section{CONCLUSÕES}

Os resultados do estudo pré-experimental permitem concluir que uma experiência positiva com websites de marcas-país influencia os consumidores na formação da imagem de um destino turístico e na intenção de visita-lo. Essa influência aparentemente ocorre via formação de conhecimento das atrações turísticas existentes no destino, bem como as atividades físicas, sociais e de contemplação possíveis de serem realizadas no local.

A capacidade que imagens e textos curtos têm de construir as associações mentais necessárias à formação tanto da imagem quanto da avaliação da atratividade de um destino turístico é o que faz de um website bem construído uma poderosa ferramenta de marketing.

Adicionalmente, os resultados deste estudo vão ao encontro do que sugere a literatura, que destaca a grande utilização da internet para planejar e organizar viagens, bem como a importância de seus recursos para a criação de uma experiência online mais prazerosa aos usuários. Conforme mostra o pré-experimento realizado, uma experiência online é capaz de tornar um destino turístico mais tangível às pessoas e de melhorar a imagem que os consumidores possuem a respeito dele.

A utilização tanto de aspectos quantitativos como qualitativos nos métodos deste estudo de natureza pré-experimental permite avaliar as relações entre a experiência online em websites de marcas-país e sua influência na formação de imagem de um destino turístico e na intenção de visitálo, diferente de trabalhos anteriores, como o de Pai et al. (2014), que avalia a navegabilidade dos websites oficiais do turismo, não se aprofundando nas influências geradas pelo website na imagem do destino ou na intenção de visitá-lo, ou de outros trabalhos que possuem ênfase na análise da imagem de destinos turísticos, mas não necessariamente a relação dela com experiências online dos consumidores (Hung et al., 2012; Hakala et al. (2013); Gao \& Bai (2014). Evidencia-se assim tanto o 
diferencial deste artigo em relação aos demais como suas contribuições à literatura dos assuntos abordados, direcionando a realização de novos estudos.

Gerencialmente, ao abordar o ponto de vista dos usuários na experiência online, este trabaIho fornece aos profissionais de turismo informações relevantes relacionadas a melhorias e boas práticas no desenvolvimento de websites de marcas-país e na disponibilização de informações a respeito de destinos turísticos pela internet, gerando novas informações sobre os aspectos valorizados pelos usuários durante a navegação em um website de marca-país, abrangendo a qualidade do conteúdo das informações do website, sua facilidade de uso, atratividade visual, e outros elementos da experiência online geral, além de aprofundar a compreensão das atividades online da marca-país islandesa, facilitando a utilização das mesmas como uma nova fonte de aprendizados e benchmarking.

A amostra formada apenas por estudantes de graduação pode ser indicada como uma das limitações do trabalho, principalmente pelo fato do perfil dos participantes ser parecido. Além disso, o estudo utilizou o website de marca-país da Islândia, país com características turísticas voltadas para frio e neve, montanha, aventura e ecoturismo. Assim, sugere-se a realização de estudos cujas amostras sejam formadas com outros públicos e/ou com um destino turístico com características diferentes das encontradas na Islândia.

\section{REFERÊNCIAS}

Aaker, D. A., Kumar V. \& Day, G. S. (2001). Pesquisa de marketing. São Paulo: Atlas.

Addis, M. \& Holbrook, M. B. (2001). On the conceptual link between mass customization and experiential consumption: an explosion of subjectivity. Journal of Consumer Behavior, 1(1), 50-67.

Alzua-Sorzabal, A., Zurutuza, M., Rébon, F. \& Gerrikagoitia, J. K. (2015). Obtaining the efficiency of Tourism Destination website based on Data Envelopment Analysis. Procedia - Social and Behavioral Sciences, 175, $58-65$.

Anholt, S. (2005). Brand new justice: How branding places and products can help the developing world. Burlington: Elsevier.

Anholt, S. (2007). Competitive identity: the new brand management for nations, cities and regions. New York: Palgrave Macmillan.

Arnould, E. J. \& Price, L. (1993). River magic: extraordinary experience and the extended service encounter. Journal of Consumer Research, 20(1), 24-45.

Baggio, R \&, Chiappa, G. D. (2014). Real and virtual relationships in tourism digital ecosystems. Information Technology \& Tourism, 14, 3-19.

Baloglu, S. \& Mccleary, K. W. (1999). A model of tourism image formation. Annals of Tourism Research, 26(1), 868-897.

Bardin, L. (2011) Análise de conteúdo. São Paulo: Edições 70. 
Brakus, J. J.; Schmitt, B. H. \& Zarantonello, L. (2009). Brand experience: what is it? How is it measured? Does it affect loyalty? Journal of Marketing, 73(3), 52-68.

Carù, A. \& Cova, B. (2007). Consuming experience: an introduction. In: Carù, A., Cova, B. (Eds.), Consuming Experience. Routledge: Abingdon.

Chen, C. F. \& Tsai, D. C. (2007). How destination image and evaluative factors affect behavorial intentions? Tourism Management, 28, 1115-1122.

Cho, Y.; Wang, R \& Fesenmaier, D. R. (2002). Searching for experiences: The Web based virtual tour in tourism marketing, Journal of Travel and Tourism Marketing, 12(4), 1-18.

Choi, S., Lehto, X.Y. \& O'leary, J.T. (2007). What does the consumer want from a DMO website? A study of US and Canadian tourists' perspectives. International Journal of Tourism Research, 9, 59-72.

Constantinides, E. (2004). Influencing the online consumer's behavior: the Web experience. Internet Research, 14(2) 111-126.

Cooper, C.; Fletcher, J.; Fyall, A.; Gilbert, D.; Wanhill, S. (2007). Turismo: princípios e prática. Porto Alegre: Bookman.

Corrêa, C. H. W. (2012) Análise das estratégias de marketing adotadas pela EMBRATUR no portal Braziltour.com. Turismo \& Sociedade, 5(1), 19-36.

Crompton, J. (1979). An assessment of the image of Mexico as a vacation destination and the influence of geographical location upon that image. Journal of Travel Research, 17 (Spring), 18-23.

Dann, G. (1996). Tourist Images of a Destination: an alternative analysis. In: Recent Advances in Tourism Marketing Research, D. R. Fesenmaier, J. T. O'Leary and M. Uysal, eds., New York: The Haworth Press.

Del Vasto-Terrientes L., Fernández-Cavia J., Huertas A., Valls A., Moreno A. (2015). Official tourist destination websites: Hierarchical analysis and assessment with ELECTRE-III-H. Tourism Management Perspectives, 15, 16-28.

Diallo, M. F. (2012) Effects of store image and store brand price-image on store brand purchase intention: Application to an emerging market. Journal of Retailing and Consumer Services, 19(3), 360367.

Diamantopoulos, A.; Schlegelmilch, B.; Palihawadana, D. (2011). The relationship between countryof-origin image and brand image as drivers of purchase intentions: a test of alternative perspectives. International Marketing Review, 28(5), 508-524.

Doolin, B.; Burgess, L; Cooper, J. (2002). Evaluating the use of the Web for Tourism Marketing: A case study from New Zealand, Tourism Management, 23(5) 557-561.

E-commerce news. (2012). Mercado de turismo movimenta o e-commerce brasileiro. Recuperado em 25 de out de 2014 de: http://ecommercenews.com.br/noticias/pesquisas-noticias/mercado-de-turismomovimenta-o-e-commerce-brasileiro-diz-comscore. 
Fakeye, P. C. \& And J. L. Crompton. (1991). Image Differences between Prospective, First-Time, and Repeat Visitors to the Lower Rio Grande Valley. Journal of Travel Research 30(2), 10-16.

Fan, Y. (2006). Branding the nation: What is being branded? Journal of Vacation Marketing, 12(1) 514.

Fan, Y. (2010). Branding the nation: Towards a better understanding. Place Branding and Public Diplomacy, v. 6(2), 97-103.

Fernández-Cavia, J., Díaz-Luque, P., Huertas, A., Rovira C., Pedraza-Jiménez, R., Sicilia, M., Gómez, L. \& Míguez, M. I. (2013). Destination brands and website evaluation: a research methodology. Revista Latina de Comunicación Social, 68, 622-638.

Fernández-Cavia, J., Rovira, C., Díaz-Luque, P. \& Cavaller, V. (2014) Web Quality Index (WQI) for official tourist destination websites. Proposal for an assessment system. Tourism Management Perspectives, 9, 5-13.

Fetscherin, M. (2010). The determinants and measurement of a country brand: the country brand strength index. International Marketing Review, 27(4), 466-479.

Gallarza, M. G., Saura, I. G.; Garcia, H. C. (2002). Destination image: Towards a Conceptual Framework. Annals of Tourism Research, 29(1) 56-78.

Gao, L. \& Bai, X. (2014). Online consumer behaviour and its relationship to website atmospheric induced flow: Insights into online travel agencies in China. Journal of Retailing and Consumer Services, 21(4), 653-665.

Gentile, C., Spiller, N. \& Noci, C. (2007). How to sustain the customer experience: an overview of experience components that co-create value with the customer. European Management Journal, 25(5) 395-410.

Groonros, C. (2004). Marketing: gerenciamento e serviços. Rio de Janeiro: Campus.

Hakala, U., \& Lemmetyinen, A. (2011). Co-creating a nation brand "bottom-up". Tourism Review, 66(3), 14-24.

Hakala, U., Lemmetyinen, A., \& Kantola, S. P. (2013). Country image as a nation-branding tool. Marketing Intelligence \& Planning, 31(5), 538-556.

Hernandez, J. M. C., Basso, K., \& Brandao, M. M. (2014). Pesquisa Experimental em Marketing. REMark: Revista Brasileira de Marketing, 13, 96-115.

Holbrook, M. (2006). The consumption experience - something new, something old, something borrowed, something sold: Part 1. Journal of Macromarketing, 26(2), 259-266.

Holbrook, M. B., \& Hirschman, E. C. (1982). The experiential aspects of consumption: consumer fantasies, feelings, and fun. Journal of Consumer Research, 9, 132-140. 
Hung , J. Y., Lin, F. L., Yang, W. G., \& Lu, K. S. (2012). Construct the destination image formation model of Macao: the case of Taiwan tourists to Macao. Tourism and Hospitality Management, 18(1), 19-35.

Hynes, N., Caemmerer, B., Martin, E., \& Masters, E. (2014). Use, abuse or contribute! A framework for classifying how companies engage with country image. International Marketing Review, 31(1), 79-97.

Jannach, D., Zanker, M., \& Fuchs, M. (2014). Leveraging multi-criteria customer feedback for satisfaction analysis and improved recommendations. Information Technology \& Tourism, 14 (2), 119149.

Knight, D. K., \& Kim, Y. K. (2007). Japanese consumers' need for uniqueness. Journal of Fashion Marketing and Management, 11(2), 270-280.

Konecnik, M., \& Gartner, W. C. (2007). Customer-based brand equity for a destination. Annals of Tourism Research, 34(2), 400-421.

Kotler, P., \& Gertner, D. O. (2004). Marketing estratégico de lugares. Dossiê HSM Management, 44, 62-93.

Li, X., Pan, B., Zhang, L., \& Smith, W. (2009). The Effect of Online Information Search on Image Development: insights from a mixed-methods study. Journal of Travel Research, 48(1), 45-57.

Malhotra, N. K. (2012). Pesquisa de marketing: uma orientação aplicada. Porto Alegre: Bookman. Nadeau, J., Heslop, L., O’Reilly, n., \& Luk, P. (2008). Destination in a country image context. Annals of Tourism Research, 35(1), 84-106.

Navidi, W. (2012). Probabilidade e Estatística para Ciências Exatas. Porto Alegre: McGraw Hill Brasil. Nebenzahl, I. D. (2007). National image and competitive advantage. In: Simpósio Internacional de Administração, 2 Congresso de Administração da ESPM. São Paulo.

OMT - ORGANIZAÇÃO MUNDIAL DO TURISMO. (2003). E-Business para o turismo. São Paulo: Bookman.

OMT - ORGANIZAÇÃO MUNDIAL DO TURISMO- UNWTO. (2014). Tourism Highlights. Recuperado em 12 de nov de 2014 de: http://dtxtq4w60xqpw.cloudfront.net/sites/all/files/pdf/unwto highlights 14 en $\mathrm{hr}$ 0.pdf.

Pai, C.-K.; Xia, M. L.; Wang, T-W. (2014) A comparison of the official tourism website of five east tourism destinations. Information Technology and Tourism. 14, 97-117.

PANROTAS. (2010) Google apresenta dados do turismo na internet. Recuperado em 30 de out de 2014 de: http://www.panrotas.com.br/noticia-turismo/tecnologia/google-apresenta-dados-doturismo-na-internet_62098.html.

Parenteau A. (1995). Destination Image: towards a conceptual framework. Annals of Tourism Research 29(1), 56-78.

Rafael, C., \& Almeida, A. D. (2014). Impacto da informação online na formação da imagem do destino virtual. Dos Algarves: A Multidisciplinary e-Journal, 23, 27-50. 
Rezende-Parker, A. M., Morrison, A. M., \& Ismail, J. A. (2003). Dazed and confused? An exploratory study of the image of Brazil as a travel destination. Journal of Vacation Marketing, 9(3), 243-259.

Rose, S., Hair, N., \& Clark, M. (2011). Online customer experience: A review of the business-to-consumer online purchase context. International Journal of Management Reviews, 13(1), 2439.

Smallman, C., \& Moore, K. (2010). Process studies of tourists'decision-making. Annals of Tourism Research, 37(2), 397-422.

Stern, E., \& Krakover, S. (1993). The formation of a composite urban image. Geographical Analysis, 25(2), 130-146.

Stock, F. (2009). Identity, image and brand: a conceptual framework. Place Branding and Public Diplomacy, 5(2), 118-125.

Tang, L. R., \& Jang, S. S. (2012). Investigating the routes of communication on destination websites. Journal of Travel Research, 51(1), 94-108.

Tasci, A. D., Gartner, W. C., \& Cavusgil, S. T. (2007). Conceptualization and operationalization of destination image. Journal of hospitality \& tourism research, 31(2), 194-223.

Thomaz, G.M.; Biz, A.A.; Bettoni, E.M.; Pavan, C.S. (2015). Modelo de monitoreo de las redes sociales para orientar en la toma de decisiones de las destination manage- ment organizations. Revista Brasileira de Pesquisa em Turismo. São Paulo, 9(2), 196-220, maio/ago.

Zeithaml, V.A.,\& Bitner, M. J. (2003). Marketing de serviços. Porto Alegre: Bookman.

Artigo recebido em: 12/09/2015. Artigo aprovado em: 01/02/2016. 


\section{APÊNDICE A \\ Questionário 1 - Pré-exposição}

\section{A) Questões Filtro:}

A1) Já viajou para o exterior? ( ) Sim ( ) Não Se sim para onde?

A2) Costuma utilizar a internet para organizar uma viagem? ( ) Sim ( ) Não

A3) Você consegue ler bem em inglês? ( ) Sim ( ) Não

B) Perfil dos respondentes e imagem do destino:

B1) Idade:

B2) Sexo: ( ) M ( ) F

B3) "Visitfrance", "visitbrasil" são exemplo de sites oficiais de destinos turísticos. Você já usou esses ou algum outro site oficial de turismo para obter informações ao programar uma viagem? ( ) Sim ( ) Não

B4) O que você sabe sobre a Islândia como destino turístico?

B5) Avalie, utilizando a escala de 1 a 10 abaixo, o quanto a Islândia é atrativa para você como destino turístico, onde 10 seria um destino muito atrativo e 1 um destino nada atrativo?

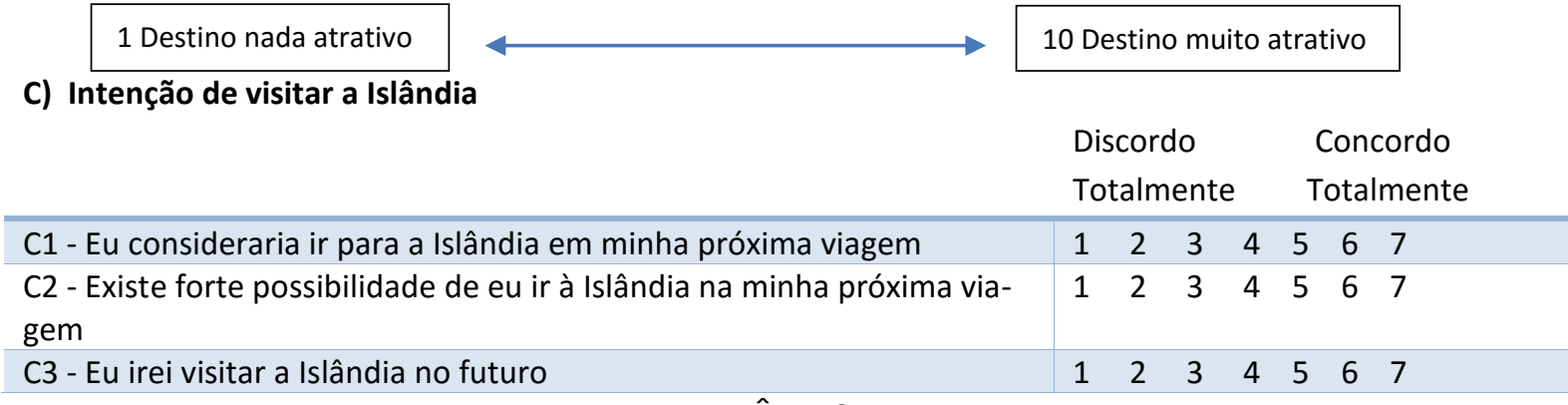

\section{APÊNDICE B}

Questionário 2 - Pós-exposição

Avalie o website ofical da Islândia que você acabou de visitar

\begin{tabular}{|l|lllllll}
\hline A) Conteúdo da informações & \multicolumn{4}{c}{$\begin{array}{c}\text { Discordo } \\
\text { Totalmente }\end{array}$} & \multicolumn{4}{c|}{$\begin{array}{c}\text { Concordo } \\
\text { Totalmente }\end{array}$} \\
\hline A1 - As informações contidas no site são convenientes & 1 & 2 & 3 & 4 & 5 & 6 & 7 \\
\hline A2 - As informações contidas no site são precisas & 1 & 2 & 3 & 4 & 5 & 6 & 7 \\
\hline A3 - As informações contidas no site estão atualizadas & 1 & 2 & 3 & 4 & 5 & 6 & 7 \\
\hline A4 - As informações contidas no site são completas & 1 & 2 & 3 & 4 & 5 & 6 & 7 \\
\hline A5 - As informações contidas no site são relevantes & 1 & 2 & 3 & 4 & 5 & 6 & 7
\end{tabular}

\section{B) Facilidade de uso}

\section{Discordo Concordo}

Totalmente Totalmente

\begin{tabular}{l|llllllll}
\hline $\begin{array}{l}\text { B1- Encontrei as informações que busquei facilmente durante a } \\
\text { navegação }\end{array}$ & 1 & 2 & 3 & 5 & 6 & 7 \\
\hline B1- A navegação é difícil, o site é complexo & 1 & 2 & 3 & 4 & 5 & 6 & 7 \\
\hline B3 - O site é bem estruturado & 1 & 2 & 3 & 4 & 5 & 6 & 7 \\
\hline B4 - O conteúdo está disposto de forma organizada & 1 & 2 & 3 & 4 & 5 & 6 & 7
\end{tabular}

\section{C) Atratividade visual}

Discordo Concordo

Totalmente Totalmente

\begin{tabular}{l|lllllll} 
C1 - Esse site é divertido & 1 & 2 & 3 & 4 & 5 & 6 & 7 \\
\hline C2 - Esse site é imaginativo & 1 & 2 & 3 & 4 & 5 & 6 & 7 \\
\hline C3 - Esse site é emocionante & 1 & 2 & 3 & 4 & 5 & 6 & 7 \\
\hline C4 - As imagens da Islândia expostas no site são atrativas & 1 & 2 & 3 & 4 & 5 & 6 & 7
\end{tabular}


Discordo Concordo

Totalmente Totalmente

D1 - As informações apresentadas no site foram suficientes para formar $1 \begin{array}{lllllll}1 & 2 & 3 & 4 & 5 & 6 & 7\end{array}$ um imagem do destino turístico

D2 - A experiência online despertou em mim o desejo de visitar a

$\begin{array}{lllllll}1 & 2 & 3 & 4 & 5 & 6 & 7\end{array}$ Islândia

D3 - As imagens e a interatividade do site me ajudaram a ter uma $\quad \begin{array}{lllllll}1 & 2 & 3 & 4 & 5 & 6 & 7\end{array}$

imagem positiva sobre o destino turístico

E) Avalie, utilizando a escala de 1 a 10 abaixo, o quanto a Islândia é atrativa para você como destino turístico, onde 10 seria um destino muito atrativo e 1 um destino nada atrativo?

1 Destino nada atrativo

10 Destino muito atrativo

F) Intenção de visitar a Islândia

Discordo Concordo

Totalmente Totalmente

F1 - Eu consideraria ir para a Islândia em minha próxima viagem $\quad \begin{array}{lllllll}1 & 2 & 3 & 4 & 5 & 6 & 7\end{array}$

F2 - Existe forte possibilidade de eu ir à Islândia na minha próxima via- $\quad \begin{array}{lllllll}1 & 2 & 3 & 4 & 5 & 6 & 7\end{array}$ gem

\begin{tabular}{l|lllllll} 
F3 - Eu irei visitar a Islândia no futuro & 1 & 2 & 3 & 4 & 5 & 6 & 7
\end{tabular}

G) Após navegar pelo site houve alguma mudança em relação à imagem que você tinha da Islândia? Se sim, descreva: 